\title{
UNA PRIMERA APROXIMACIÓN AL LIBRO DE ENTERRAMIENTO DEL CONVENTO DE SAN CARLINO ALLE QUATTRO FONTANE DE ROMA
}

\author{
A FIRST APPROXIMATION TO THE BURIAL'S \\ BOOK OF THE CONVENT OF SAN CARLINO \\ ALLE QUATTRO FONTANE IN ROMA
}

\author{
MARÍA JOSÉ COLLADO RUIZ \\ CICOP Andalucía
}

\begin{abstract}
Resumen: Con este artículo se pretende restituir parte de la historia funeraria desarrollada durante algo más de dos siglos en la iglesia del convento de San Carlino alle quattro Fontane de Roma. Para ello se ha realizado un estudio exhaustivo del libro de enterramientos que se conserva en el archivo del convento, tanto de los registros de las sepulturas de los difuntos seglares como de un plano de la planta que se ha incluido en dicho libro. Se obtiene de esta forma una primera aproximación a la actividad funeraria llevada a cabo en esta iglesia trinitaria española en suelo italiano.

Palabras clave: Roma, Orden Trinitaria, España, San Carlino, enterramiento.

Abstract: This article aims to restore part of the funeral story developed during two centuries in the convent of San Carlino alle Quattro Fontane in Rome. This has made an exahustive study of the book of burials, the records of the secular graves and the plan included in the book. Obtained this way a first approximation to activity funeral held in this Spanish Trinitarian church on Italia.

Keywords: Roma, Trinitarian Order, Spain, San Carlino, burial.
\end{abstract}

Cuando en una visita por Roma, nos reservamos un día para deleitarnos con el magnífico arte barroco que caracteriza a la ciudad eterna, es parada obligada la iglesia de los trinitarios españoles, conocida popularmente como San Carlino alle Quattro Fontane. Este último adjetivo se puede descubrir desde la calle, al encontrarse ubicada en el cruce de las calles Pía y Felice (actualmente Vía Venti Settembre y Vía delle Quattro Fontane), donde cada una de las esquinas se halla decorada con una fuente. Sin embargo, debemos entrar en el interior del templo para entender cuál es el significado del diminutivo que se ha aplicado a la advocación 
de San Carlos Borromeo. Las pequeñas dimensiones del mismo le han hecho famoso, no sólo por el alarde compositivo del arquitecto que lo diseñó sino porque se suele relacionar como anécdota que este tendría cabida en uno de los pilares que sostienen la cúpula de San Pedro del Vaticano.

Hablar de San Carlino implica una obligada referencia a la actividad de Borromini, ya que esta se ha considerado, fuera de toda duda, su obra maestra. Ese trabajo largamente anhelado por el maestro que por primera vez se encuentra ante un encargo autónomo y que en principio parecía tener el suficiente apoyo económico como para que llegara a término, tenía como mayor dificultad la de la escasa superficie que tenía el solar y las impuestas limitaciones geométricas que le generaba el trazado urbano, a lo que se añadió que debía desarrollar todo el programa de necesidades que tenía un edificio conventual: iglesia, claustro y dependencias para los religiosos. Aún así, era la oportunidad para hacer manifiesto su genio.

Sobre las vicisitudes y los resultados de la tarea proyectual de Borromini se han escrito muchas y muy buenas disertaciones en las últimas décadas y es posible que recrearnos en ellas resultase una tarea poco original y carente de sentido en este trabajo ${ }^{1}$. Lo que seguramente podamos destacar es que el sumo cuidado con que trató los detalles en el diseño de todas las estancias de este convento, no llevaron a que se olvidase de dedicarle similar atención a un espacio que muchos podrían considerar secundario, como era el destinado a ser receptáculo de los cuerpos sin vida de los frailes trinitarios y de algunos fieles que optaran por este, y no otro, como lugar de enterramiento.

Fruto de la consideración debida a este espacio es la denominación que recibe este lugar en el convento trinitario. No se le menciona como cementerio, ni cripta, ni de ningún otro modo que resulte una alusión directa a su finalidad como espacio de enterramiento, sino que se le llama "iglesia subterránea" o como algunos han traducido "iglesia inferior".

En 1634 dan comienzo las obras del convento y cuatro años más tarde se inicia la iglesia, en la que se desarrolló un diseño sumamente complejo manteniendo el eje principal desde la entrada hasta el presbiterio, imprimiendo un importante movimiento a la fabrica articulando un sinuoso contorno que se completaba con sencillas columnas empotradas en el muro que iban separando los distintos frentes del altar y capillas hornacinas.

${ }^{1}$ P. PORTOGHESI, Borromini. Architettura come linguaggio, Milano, 1994. R. BÖSEL, C.L. FROMMEL (a cura di), Borromini e l'universo barroco, Milano, 2000. 
La llamada "iglesia subterránea” se desarrolla en esencia en idéntica disposición a la iglesia, destacando el eje principal con un pequeño frente de altar decorado con una pintura al fresco. En el alzado murario se distribuyen una serie de capillas o nichos que alternan el perfil adintelado con el semicircular, sobre las que se insertan estructuras de lunetos que se cierran en una bóveda muy rebajada. El tratamiento ornamental de este espacio es mínimo y se reduce al propio movimiento de las paredes que los cierran y a una cornisa que de forma continua la recorre en su totalidad, una curva de importante movimiento y resalto que produce un singular efecto ante la total visión del espacio subterráneo. En principio y dado el aspecto que presenta en la actualidad tras varias intervenciones restauradoras recientes no queda reconocible a simple vista la intensa actividad funeraria que se llevo a cabo en este lugar. Ya que de forma testimonial se han mantenido algunas pequeñas placas cerámicas con las antiguas numeraciones asignadas a las sepulturas y sólo dos lápidas de mármol blanco a los pies de esta pequeña iglesia ${ }^{2}$. Hay un único espacio diferenciado en el lateral noreste que se eleva mediante un par escalones y que en principio se podría pensar que se ideó con la intención de señalar un enterramiento o enterramientos especiales, entre ellos uno para el propio Borromini tal y como apunta Anthony Blunt ${ }^{3}$. Aspecto este sobre el que no existe un total consenso, aunque lo que es un hecho probado es que finalmente este acabaría recibiendo sepultura en la Iglesia de San Giovanni dei Fiorentini muy cerca de su admirado Maderno.

Una fuente básica para esta investigación ha sido la consulta del libro de enterramientos de San Carlino que se conserva en el archivo de dicho convento. En este hay un doble registro, por un lado los enterramientos de religiosos y los de seglares, que por tanto, tiene en correspondencia una foliación independiente para unos y otros, y un índice también doble ordenado alfabéticamente en que se registran todos los difuntos que fueron sepultados en el convento romano hasta la segunda mitad del siglo XIX ${ }^{4}$. A partir de entonces se siguen anotando sólo los de religiosos y el lugar en el que recibieron sepultura, siendo el último el realizado en 1998 en el cementerio de Campo Verano, donde actualmente la congregación tri-

\footnotetext{
2 P. DEGNI, "San Carlino alle Quattro Fontane. Annotazioni circa le opere di restauro eseguite e in corso. Roma 1986-1998”, AR 24, 21 (1999), pp. 42-46.

${ }^{3}$ A. BLUNT, Borromini, Madrid, 1987, p.69.

${ }^{4}$ Los índices no van foliados y van ordenados alfabéticamente por la letra de inicio del nombre. En ellos se indica el folio y el número de la anotación. A pesar de esto el índice tiene algunos olvidos y no es del todo inmediato ya que por ejemplo coloca en la letra $\mathrm{H}$ nombres que en los registros ha escrito sin ella, fruto de la falta de normalización ortográfica de este periodo y de la indistinta utilización de algunos términos o nombres en italiano y español.
} 
nitaria tiene un pequeño espacio funerario ${ }^{5}$. Hemos de reseñar la salvedad de que en la parte dedicada a los “defonti secolari” hay también anotaciones de sacerdotes y religiosos, pero no integrantes de la comunidad trinitaria.

Aunque todas las anotaciones no son igual de rigurosas, aportan una valiosa información de la particular actividad funeraria que se vino realizando en la iglesia de este convento durante prácticamente dos siglos.

Por las primeras que se encuentran en la parte dedicada a los difuntos seculares se puede llegar a la conclusión de que antes de comenzar a practicarse los enterramientos en la que ahora se conoce como "iglesia subterránea" se debieron realizar en otro lugar del convento. Aunque este es un aspecto sobre el que este libro no arroja mucha luz y es posible que cuando se escribe que se enterró a alguien “en el suelo antiguo antes de que se hicieran los números” se esté refiriendo a que se practicaron los sepelios en el mismo lugar donde en pocos años se acabaría de ejecutar la cripta con delimitación de sepulturas y su preceptiva identificación. De hecho hay anotaciones de este tipo hasta diciembre de 1643, a pesar de que en la primavera de 1642 y 1643 se registran tres enterramientos en los que se aporta el número de la sepultura que se les asignó ${ }^{6}$.

Esta falta de claridad en los registros ayuda poco a conocer como era la práctica funeraria antes de tener totalmente operativa la cripta bajo la iglesia y parece apuntar dos hipótesis distintas. Por un lado el desconocimiento de la fecha en la que se comienza a dar forma a este libro de enterramientos que puede que copiara alguna información registrada en otro anterior, el que se estuvieran utilizando lugares diferentes para acoger a los difuntos mientras no se tenía acabada la obra de la iglesia subterránea o el que incluso no se hubieran demarcado y señalado en la cripta los distintos enterramientos en una primera fase.

La frecuencia de enterramientos no era muy alta en San Carlino. No se llega a la media de un entierro al año, sumando los sepelios de los propios trinitarios, que no elevarían especialmente la proporción dado que desde 1643 hasta el final de este siglo sólo se realizan quince. Aun así el primer aspecto que se señala en el libro de enterramientos es el de la reserva o separación de un determinado número

${ }^{5}$ ASC (Archivo San Carlino). Libro de enterramientos. Foliación doble, a la que asignaremos la inicial R para religiosos y S para seglares. Aprovechar la primera mención al Archivo de los trinitarios españoles en Roma para agradecer la inestimable ayuda y facilidades que ofreció su prior F. Pedro Aliaga y la colaboración de Giulia Guerriero en la traducción del texto en italiano.

${ }^{6}$ ASC, Libro de enterramientos. Seculares, fol. 1r. La segunda anotación es de 1639 y se explica que se hico en el "suolo antico avanti, che si matonasse e si facessero li numeri". Fol. 1v. En marzo y diciembre de 1643 se recoge alto parecido: "nel suolo antico avanti se facessero li numeri", sin embargo en otras anotaciones de marzo y mayo de 1643 se explicita que se hicieron "tra il no 12 e 13 " y "sotto il no 25 ". 
de sepulturas para los religiosos. Las seis primeras que se distribuían en los dos tramos más cercanos al altar son las que se denominan como “depósito de religiosos” y en contadas ocasiones se cedían para enterrar a algún personaje laico o eclesiástico que no perteneciese a la familia trinitaria.

Básicamente estos casos excepcionales se podían reducir a unos determinados tipos de difuntos, entre los que se destacan los eclesiásticos como el obispo de Nusco, D. Angelo Giordano Picetti en $1668^{7}$, enterrado en la número tres o el fraile benedictino F. Benedetto Olaz en $1711^{8}$. También los hermanos Giampe, Pietro que era beneficiado de la basílica de San Pedro y el abad Ignacio Giampe ocuparan las sepulturas de los trinitarios en $1720^{9}$ y $1726^{10}$ respectivamente. En 1731 se entierra al sacerdote piamontés Felipe de la Torre en la sepultura número tres sobre la caja de un fraile ${ }^{11}$ y en la que años antes habíamos visto se enterró al obispo de Nusco y en 1805 recibirá sepultura en una de las reservadas a los trinitarios un sacerdote jesuita $^{12}$. Hay uno especialmente señalado entre todos estos y es de la sepultura que se concedió al Cardenal Denoff en la iglesia subterránea en el año $1697^{13}$. En el libro de enterramientos se menciona que fue en la número seis ${ }^{14}$, sin embargo en otra anotación posterior se señala que sus restos mortales estaban en la uno ${ }^{15}$.

Hay otras personas a las que también se les dio cabida en estos enterramientos. Como ocurrió en la número cinco que recibió los cuerpos de un caballero romano que no se identifica en $1738^{16}$ y en 1743 el de Ambrosio Albizu, copero del Cardenal Albani ${ }^{17}$. Mención aparte y destacada, si nos hacemos eco de la larguísima anotación que se le dedica en el registro de los enterramientos fue el de Don

\footnotetext{
${ }^{7}$ ASC, Libro de enterramientos. S., fol. 2v.

${ }^{8}$ ASC, Libro de enterramientos. S., fols. 7r-7v anotación 18.

${ }^{9}$ ASC, Libro de enterramientos. S., fols. 8r-8v.anotación 55.

${ }^{10}$ ASC, Libro de enterramientos. S., fols. 9r-9v. anotación 62.

${ }^{11}$ ASC, Libro de enterramientos. S., fols. 10r-10v. anotación 67.

12 ASC, Libro de enterramientos. S., fol. 18r. anotación 116- curiosa porque está escrita en español...

${ }^{13}$ El Cardenal Casimiro Denoff, polaco, pudo permanecer en Roma desde 1691, fecha en la que se celebró el conclave del que resultó elegido Papa Alejandro VIII y en el que consta que participó.

${ }^{14}$ ASC, Libro de enterramientos. S., fol. 4v. anotación 34.

${ }^{15}$ ASC, Libro de enterramientos. S., fol. 5v. anotación 42. En el registro del enterramiento del hijo del Duque de Uceda en la sepultura número uno se señala que en esta reposaban los restos del Cardenal Denoff.

${ }^{16}$ ASC, Libro de enterramientos. S., fols. 11v-12r. anotación 77. Sólo se dice que se enterró al caballero romano Sr. D. Benedetto Caputti y la donación que hizo al convento para que se celebrará por él un aniversario perpetuo.

${ }^{17}$ ASC, Libro de enterramientos. S., fols. 12r-12v. anotación 81.
} 
Antonio Pacheco del hijo del Duque de Uceda en 1703 en la sepultura número uno $^{18}$, donde ya estaban los restos del Cardenal Denof como anteriormente citamos.

Son estos dos últimos casos tan singulares, los que se tratarán más largamente en el transcurso de este artículo, ya que ambos serán de los más ilustres ocupantes del cementerio trinitario. Sin embargo, también es interesante prestar atención a los enterramientos que se cedieron a algunas mujeres en este espacio reservado para los frailes.

A la vista de las excepciones que hemos visto en el libro de enterramientos es obvio que se consintió compartir tan privilegiado espacio a muy pocas de ellas, entre las que tendrán fácil justificación aquellas que se integraron en la familia trinitaria en alguna de sus secciones femeninas. Así en 1763 se da sepultura en la número dos a la hermana María Victoria Campanni ${ }^{19}$ y en la número tres en 1819 a la también religiosa y superiora de la Escuela Pia Trinitaria Serafina de Jesús ${ }^{20}$. En virtud de lazos consanguíneos se enterró en la número cinco a la madre de un religioso de San Carlino en $1783^{21}$.

Muy destacados fueron los espacios funerarios concedidos a la Marquesa Constanza Toruci de Ormani en $1726^{22}$, de quién se especifica que se la enterró en una sepultura virgen entre las dos primeras, más cercanas al altar mayor, que eran el lugar de privilegio por excelencia en la iglesia subterránea y el de la Sra . Franchesca de Marchis a quien en 1751 se la sepultó en la número cuatro ${ }^{23}$. Pero entre estos cabe reseñar especialmente el de $\mathrm{D}^{\mathrm{a}}$. Laura Martinozzi Mazarini, Duquesa de Modena, y como tantas veces se explica en el libro de enterramientos, era madre de la Reina de Inglaterra. Esta señora, que había optado por abandonar prácticamente la vida pública en sus últimos años y vivía retirada en Roma, mantuvo una gran cercanía con el convento y con la orden de los trinitarios españoles, de ahí que dispusiera que su cuerpo se enterrará en el mismo en 1687, donde ya estaban los restos de su madre $\mathrm{D}^{\mathrm{a}}$. Margarita Martinozzi Mazarini ${ }^{24}$. El trato dispensado por la comunidad a tan noble dama le llevó a ocupar uno de los espacios reservados a los religiosos, aún conociendo estos la posibilidad de que se tratará en reali-

\footnotetext{
${ }^{18}$ ASC, Libro de enterramientos. S., fols. 5v-6r. anotación 42.

${ }^{19}$ ASC, Libro de enterramientos. S., fols. 14r-14v. anotación 93.

${ }^{20}$ ASC, Libro de enterramientos. S., fol. 19r. anotación 123.

${ }^{21}$ ASC, Libro de enterramientos. S., fol. 16r. anotación 102.

${ }^{22}$ ASC, Libro de enterramientos. S., fol. 10r. Anotación 64.

${ }^{23}$ ASC, Libro de enterramientos. S., fol. 13r. anotación 86.

${ }^{24}$ ASC, Libro de enterramientos. S., fol. 3v. anotación 29. Muere esta dama el 9 de julio de 1685 y es enterrada al día siguiente.
} 
dad de un depósito como finalmente ocurrió ya que sus restos mortales serían trasladados hasta Modena unos años después ${ }^{25}$.

Dos mujeres más recibieron sepultura en las tumbas reservadas a los trinitarios, en 1789 Marguerita Cappelleti ${ }^{26}$ y en 1814 Ana Maria Berandi ${ }^{27}$ de quienes se destacan su ejemplar virtud y piedad. Características que debemos entender las hicieron ganarse tan destacado lugar entre las sepulturas de los mismos frailes del convento.

Aparte de los enterramientos que la comunidad reservaba a sus propios miembros fueron muy pocas las sepulturas que se den en propiedad a particulares. Sólo el que fuera médico de los trinitarios descalzos D. Francisco Raniero Perazzani tuvo una que se consolidó como espacio funerario de su familia. Aunque no se deja constancia del modo en que se realizara esta donación-transacción, debió influir considerablemente que este prestaba sus servicios a los religiosos sin obtener remuneración alguna. Se le concedió una sepultura que quedaba bajo el altar de Jesús Nazareno tal y como consta en una de las anotaciones del libro de enterramientos que se realiza en 1736 con motivo del sepelio de su hijo Vincenzo ${ }^{28}$. Concretamente la número veinticinco en la que se debió colocar una lápida en que se hacía constar la propiedad de la misma. En 1758 será el propio médico quien ocupe esta sepultura $^{29}$. Sin embargo en 1764 se enterrará a su hija en la sepultura número diecisiete ${ }^{30}$. A partir de esta fecha se repiten varios registros de sepelios de miembros de esta familia y se producen ligeras variaciones a la hora de ubicar el espacio concreto en el que se enterraron ${ }^{31}$, solo en 1797 se aclara que uno de ellos se entierra en la número treinta y uno porque había transcurrido poco tiempo desde que la sepultura familiar se había abierto para acoger un nuevo cuerpo ${ }^{32}$. A pesar de esta falta de concreción lo que si podemos deducir es que el altar dedicado al Nazareno se encontraba en el lateral del evangelio de la Iglesia de San Car-

${ }^{25}$ ASC, Libro de enterramientos. S., fols. 3v-4r. anotación 30. Se añade en el registro de esta sepultura que el 6 de septiembre de 1695 se exhumó su cadáver y se trasladó a la ciudad de Modena, actuando como agente del Duque, su hijo, el abad Fossi. Este hecho se registró en un acta notarial que no ha sido posible localizar entre la documentación del archivo trinitario.

${ }^{26}$ ASC, Libro de enterramientos. S., fol. 17r. anotación 108.

${ }^{27}$ ASC, Libro de enterramientos. S., fol. 18v. anotación 121.

${ }^{28}$ ASC, Libro de enterramientos. S., fol. 11v. anotación 75.

${ }^{29}$ ASC, Libro de enterramientos. S., fol. 13v. anotación 90.

${ }^{30}$ ASC, Libro de enterramientos. S., fol. 15r. anotación 94.

31 ASC, Libro de enterramientos. S., fol. 17v. anotación 112. Registro del enterramiento de Michele Perazzani el 27 de marzo de 1795 entre la sepultura 17 y 25. Fol. 17v. anotación 113. Registro del enterramiento de una niña de solo tres años hija del anterior el 15 de octubre de 1796 “en la sepultura de la familia”.

${ }^{32}$ ASC, Libro de enterramientos. S., fol. 17v. anotación 115. 
lino y que justo debajo es donde recibieron la propiedad funeraria los miembros de la familia Perazzani.

Con el "spedizionere di lettere apostoliche" de la Cancilleria Vaticana, el navarro D. Manuel Donado, se produce un caso similar. En mayo de 1727 entierra a su hija "nella loro propria sepoltura al $n^{\circ} 32$ "33. Ahora bien, cuando años más tarde se registra el entierro de otra de sus hijas se referenciará la sepultura " $\mathrm{n}$ " 22 "34. Esta diferencia puede deberse a un error por parte del fraile que copia los antiguos registros en el nuevo libro, que sin embargo aporta una información esencial, y es su ubicación bajo la capilla de San Francisco de Paula. Muy poco tiempo después el Sr. Donado vuelve a enterrar a otro de sus vástagos y ahora recibirá tierra en la número dieciséis ${ }^{35}$, aunque en este caso puede explicarse por la proximidad de los últimos sepelios y la imposibilidad de volver abrir la tumba recientemente ocupada. En 1758 será el titular, Don Manuel Donado quien fallezca y tenga que enterrarse en una sepultura cercana a la que la comunidad le había concedido a él y a sus herederos ${ }^{36}$. Entre los datos que aporta el fraile que anota este entierro se señala que dicho señor era muy devoto de San Francisco. En registros posteriores sobre el enterramiento de su viuda ${ }^{37}$ y su nieta ${ }^{38}$ se señala la sepultura numero dieciséis. A la vista del dibujo de la planta de la iglesia subterránea que incluye el libro de enterramientos del convento quedan aún más patentes las inconcreciones que se producen con esta información, pero lo que parece quedar más claro en que en lateral de la epístola es donde estaba la capilla dedicada a San Francisco de Paula bajo la cual tuvieron sepultura propia los miembros de la familia Donado.

No se especifica que se les diera sepultura en propiedad, pero algunos fieles procuraran que su enterramiento se haga junto al de algún familiar. En 1723

${ }^{33}$ ASC, Libro de enterramientos. S., fol. 10r. anotación 66.

${ }^{34}$ ASC, Libro de enterramientos. S., fol. 12v. anotación 82.

35 ASC, Libro de enterramientos. S., fol. 12v. anotación 84. Registro del entierro de Lorenzo Donado el 7 de agosto de 1745 en la sepultura 16 "attacata la testa alla sepultura de la sua sorella Maria Antonia Donado”.

${ }^{36}$ ASC, Libro de enterramientos. S., fol. 13v. anotación 89.

${ }^{37}$ ASC, Libro de enterramientos. S., fol. 15r. anotación 95. Registro del enterramiento de Orsola Donado viuda de D. Manuel Donado el 17 de agosto de 1764. Se añade se asignó la número 16 bajo el altar de San Francisco de Paula por estar la sepultura familiar recientemente ocupada por el cadáver de su consorte. Lo que extraña a la vista de otras prevenciones similares en las que se ha respetado un periodo de tiempo menor.

${ }^{38}$ ASC, Libro de enterramientos. S., fol. 23v. anotación 134. Registro del entierro el 4 de febrero de 1847 de Teresa Pacetti hija de Gaetano González y Eugenia Donado (hija de D. Manuel Donado). 
Leoncia Georgi recibe sepultura en la número cuarenta y tres ${ }^{39}$ y diez años después lo hará su hermana ${ }^{40}$. En 1836 se entierra a Anna Anivitti entre las últimas sepulturas de la iglesia subterránea, las que quedan a los pies de la misma, numeradas con el cuarenta y tres y cuarenta y cuatro ${ }^{41}$. En 1851 una niña de la familia se enterrará en la cuarenta y tres y en esta misma se coloca a su hermano el año siguiente $^{42}$. Don Francesco Anivitti en 1858 será enterrado junto a su madre en la número cuarenta y cuatro ${ }^{43}$ y su hermana Petronila Anivitti a su lado en $1859^{44}$.

De estas han quedado como testimonio unas lápidas en la solería de la cripta. Una es la de la sepultura de la madre. Primer miembro de esta familia del que quedó constancia de su enterramiento en San Carlino y de Pio un niño que murió con sólo cuatro años de edad, tal y como se grabó en un epitafio en latín que al modo clásico informa que Pio Anivitti Romano de cuatro años, cinco meses y veintiséis días murió el veinticinco de marzo de 1852. Esta cuenta con la única decoración de un crismón entre las letras alfa y omega. Al igual que el de Anna Anivitti, que también incluye un sencillo escudo de armas en la parte superior y un memento mori (calavera sobre tibias cruzadas y una guadaña) en la parte inferior.

Estas son las únicas que se han conservado en lo que debía ser su emplazamiento original, ya que las sucesivas campañas de restauración y la pérdida del uso cementerial de este espacio ha hecho que sean muy escasos los testimonios de este interesante pasado funerario. En la actualidad se han dejado testimonialmente algunas de las pequeñas placas numeradas que señalaban las distintas sepulturas, una que referencia el lugar donde estuvo sepultado el Cardenal Denoff y un pequeño frente de un sepulcro de uno de los religiosos de la comunidad en que apenas se lee su nombre y parte de la fecha de defunción. Fray Giuseppe de la Santísima Trinidad que murió según consta en el libro de enterramientos el 4 de julio de 1860 y fue enterrado en el nicho número uno ${ }^{45}$.

\footnotetext{
${ }^{39}$ ASC, Libro de enterramientos. S., fol. 9r. anotación 59.

${ }^{40}$ ASC, Libro de enterramientos. S., fol. 10v. anotación 69. Registro del enterramiento el 23 de febrero de 1733 de la Sra. Umana Giorgi.

${ }^{41}$ ASC, Libro de enterramientos. S., fol. 23r. anotación 132.

${ }^{42}$ ASC, Libro de enterramientos. S., fol. 24r. anotación 135. Teresa Anivitti de sólo dos años es enterrada el 13 de marzo de 1851. Antotación 136. Su hermano Pio de cuatro años es enterrado el 16 de marzo de 1852 y según se recoge, justo “delante de su hermana” se entierra este niño.

43 ASC, Libro de enterramientos. S., fol. Fol 24r. anotación 137. Se registra el entierro del canónigo D. Franceso Anivitti y su entierro el 25 de octubre de 1858.

${ }^{44}$ ASC, Libro de enterramientos. S., fol. 24r. anotación 138. Registro del entierro el 2 de febrero de 1859 de Petronila hermana del canónigo antes citado.

${ }^{45}$ ASC, Libro de enterramientos. R., fol. 32r. Anotación 73.
} 
La relación que muchos fieles establecieron con el convento se tradujo no sólo en la elección de su lugar de reposo eterno entre sus muros, sino también en la dotación de memorias de misas y distintos legados piadosos. No es el cometido del libro de enterramientos llevar la contabilidad de este tipo de donaciones e inversiones piadosas, pero algunas serán reseñadas en el mismo. De hecho hasta la anotación número setenta y seis no aparece un difunto que deje una limosna para el convento. En este caso un caballero romano que recibió sepultura en una de las reservadas para los frailes y que dotó un aniversario perpetuo ${ }^{46}$. Lo más usual es que ofrezcan un "luogo di monte" con el que obligan al convento a decir una serie de misas al año, como hizo Margherita Baltieri en $1753^{47}$ o Giovanna Salseti, que pidió expresamente que se oficiaran en altares privilegiados ${ }^{48}$. Rosa Marazzi fundó dos aniversarios cantados ${ }^{49}$.

Silvia Catherina Lecini dejó un legado de dos misas cada viernes del año en el altar de Jesus Nazareno ${ }^{50}$, también la Sra. Vittorial Romanelli financiaría en esta iglesia la celebración de un triduo a Jesus Nazareno anualmente ${ }^{51}$. La devoción suscitada por esta imagen la hizo merecedora de donaciones muy especiales como la de la Sra. Anna Fascivoli que le dejó un anillo con diamantes ${ }^{52}$.

La devoción a San Francisco de Paula también movilizó los legados piadosos de algunos fieles enterrados en San Carlino, como los realizados por los miembros de la familia Donado que adquirieron los derechos de una sepultura bajo el altar de este santo. Y el cabeza de familia, Enmanuel Sebastiano Donado llevaba treinta años costeando la fiesta solemne que se le celebraba anualmente con triduo, exposición del Santísimo y servicio de música ${ }^{53}$.

${ }^{46}$ ASC, Libro de enterramientos. S., fols. 11v- 12r. anotación 77.

${ }^{47}$ ASC, Libro de enterramientos. S., fol. 13r. anotación 87. Se recoge en este registro además de la fecha de la sepultura el 16 de abril de 1753 la información de que la renta generada por este crédito se emplee en decirle 12 misas al año y especificar que la limosna por cada una será de 15 baiocchi.

${ }^{48}$ ASC, Libro de enterramientos. S., fols. 13r-13v. anotación 88. Enterrada el 4 de octubre de 1756 en la sepultura número 38 dejó como carga piadosa el decirle al año 12 misas en altares privilegiados.

${ }^{49}$ ASC, Libro de enterramientos. S., fol. 16v. anotación 104. Rosa Marazzi enterrada el 17 de septiembre de 1785 en la sepultura número 9.

${ }^{50}$ ASC, Libro de enterramientos. S., fol. 16r. anotación 99. Enterrada el 23 de enero de 1773 bajo la capilla de Jesús Nazareno dotó dos misas que se debían celebrar cada viernes en este altar en sufragio de su alma y la de su esposo Ferdinando di Laurentis.

51 ASC, Libro de enterramientos. S., fol. 23v. anotación 133. Enterrada el 15 de enero de 1836 en la sepultura número 40.

${ }^{52}$ ASC, Libro de enterramientos. S., fol. 15r. anotación 97. Enterrada el 14 de noviembre de 1764 en la sepultura número 35.

53 ASC, Libro de enterramientos. S., fol. 13v. anotación 89. Registro del enterramiento de D. Enmanuelle Sebastiano Donado el 20 de mayo de 1758 en que se incluye la especial devoción que 


\section{MARÍA JosÉ Collado RuIZ \\ UNA PRIMERA APROXIMACIÓN AL LIBRO DE ENTERRAMIENTOS...}

No se pueden encontrar legados de tipo artístico más que los que dejó al convento una hermana de la orden con un pequeño cuadro representando a Santa Ana y la Virgen ${ }^{54}$. Uno que seguramente sería muy apreciado por los religiosos fue el de una urna con reliquias de diversos santos que hizo Enmanuel Donado y del cual se dio testimonio en el registro del enterramiento de su hijo Lorenzo en $1745^{55}$. Igualmente sólo hay un caso en que se haya hecho una mención expresa a que alguna persona tuviera la previsión de que su cuerpo se adornara con algún rico complemento o una mortaja especial. Sin embargo se hace una llamada de atención al sepulturero con la Sra. Catherina Clementi, dama de la Princesa de Palestrina que fue enterrada en 1741 en una caja de madera "con todo lo que llevaba advirtiéndolo al sepulturero" 56 lo que podía llevarnos a pensar que pudiera haberse ataviado con algo valioso.

Las relaciones que se establecían con San Carlino a la hora de optar por su iglesia subterránea como lugar de reposo eterno resultan de lo más variadas. Así el procurador secular del convento, D. Giuseppe Antonio Rainaldi enterró a dos hijas en 1722 y $1726^{57}$, aunque no hay constancia de que nadie más de su familia ni él mismo acabaran recibiendo sepultura aquí. Por ejemplo dos de los albañiles que trabajaron en las prolongadas obras del convento fueron sepultados en su cripta, el maestro Gio Mariotti en el año $1726^{58}$ y en 1787 Giuaquino Bertazi que contaba con una alta estima por parte de la comunidad y en atención a su devoción a Jesús Nazareno le entierran bajo su altar ${ }^{59}$. No parece existir igual grado de afinidad en cuanto a la sepultura en que se enterró en 1737 a otro maestro del trabajo en mármol que dejó una importante limosna para sufragar un buen número de misas por su alma ${ }^{60}$.

profesaba a San Francisco de Paula y el tiempo que llevaba sufragando una fiesta solemne anual el día de dicho santo.

${ }^{54}$ ASC, Libro de enterramientos. S., fol. 15v. anotación 98.

${ }^{55}$ ASC, Libro de enterramientos. S., fol. 12v. anotación 84.

${ }^{56}$ ASC, Libro de enterramientos. S., fol. 12r. anotación 79. Se registra la fecha de su entierro el 31 de diciembre de 1741 en la sepultura número 20 y la advertencia que se hizo al sepulturero: "con tutto cuanto portava adosso advertenza, que fecci al beccamorte".

${ }^{57}$ ASC, Libro de enterramientos. S., Fols. 8v y 9r. anotaciones 58 y 61 . Entierros el 30 de julio de 1722 y el 9 de marzo de 1726 de dos niñas del procurador secular del convento en las sepulturas 17 y 32 respectivamente.

${ }^{58}$ ASC, Libro de enterramientos. S., fol. 10r. anotación 65.

${ }^{59}$ ASC, Libro de enterramientos. S., fols. 16v-17r. anotación 106. Se le enterró entre la sepultura número 27 y la 25.

${ }^{60}$ ASC, Libro de enterramientos. S., fol. 11v. anotación 76. El 25 de noviembre de 1737 se enterró en la sepultura 21 a Giuseppe Rosi “artebianca” de la Fontana de Trevi que dotó una memoria de 400 misas. 
Al comenzar el estudio el libro de los enterramientos de San Carlino surge inmediatamente la posibilidad de investigar hasta que punto, esta iglesia de los trinitarios descalzos pudo haberse convertido en un pequeño refugio para los restos mortales de algunos de los muchos españoles que por esas fechas formaban una numerosa colonia en Roma. Ante esta hipótesis se ha de ser lo suficientemente cuidadoso para tomar dos importantes aspectos en consideración. Por un lado el que en esta ciudad había otras muchas iglesias que denominaremos nacionales por las que podían haberse decantado: las dos más importantes serían las de Santiago y Santa María in Monserrato y que además estos no eran los únicos religiosos que tenían su casa en Roma y por tanto sus iglesias podían haberles acogido perfectamente. A lo que se debe añadir la protección que supone para cualquier fiel su propio ámbito parroquial que pone a su disposición un espacio para darle sepultura, independientemente de orígenes nacionales.

Pero aún hay un aspecto más por contemplar: y es hasta qué extremo se puede extender la denominación de españoles en los siglos que abarca el libro de enterramientos de este convento. Los propios frailes que registran los entierros en este libro usan en algunas ocasiones la palabra español para referirse a alguno de los difuntos, pero es más habitual que utilicen la del reino o región de procedencia. Así hablaran de navarros, del reino de Mallorca, naturales de Murcia, de la ciudad de Baeza,... ¿y qué podemos decir de los que a priori se pueden generalizar bajo el epígrafe de italianos? Esta es una denominación que no aparece en el libro y que vuelve a incidir en el lugar de procedencia que ya hemos señalado. Así se citan, como parece normal muchos personajes romanos, pero igualmente se señalan a otros oriundos de lugares de la actual Italia que por aquellas fechas eran territorios gobernados por la monarquía española. Así hay difuntos de Nápoles y Sicilia, entre otros.

Aún con estas salvedades de partida, se podría pensar que algunos españoles tuvieron con este monasterio una particular relación que les llevó a elegirlo como lugar de sepultura para sus familiares o ellos mismos. Así es como se dan algunos casos particulares como los de los hijos de algunos de los artistas que durante largo tiempo residieron y se formaron en el extranjero al amparo de las prestigiosas becas y ayudas que proporcionaban las Academias de Bellas Artes: José de Madrazo y José Álvarez. Ambos formaron parte del circulo cortesano que se creó en Roma en torno a los exiliados reyes españoles Carlos IV y María Luisa de Borbón ${ }^{61}$. Así es como en sólo dos años quedó constancia en este registro del conven-

\footnotetext{
${ }^{61}$ B. DE PANTORBA, Los Madrazo, Barcelona, 1947, p. 11.
} 


\section{MARÍA JosÉ COLLAdo RUIZ \\ UNA PRIMERA APROXIMACIÓN AL LIBRO DE ENTERRAMIENTOS...}

to que el pintor José de Madrazo enterró a dos de sus hijos en la iglesia subterránea de San Carlino ${ }^{62}$. Y poco después hará lo propio, también con dos de sus hijos, el escultor José Álvarez ${ }^{63}$.

Hay más casos de fieles españoles que muriendo en Roma optaron por San Carlino como lugar de descanso eterno ${ }^{64}$. En 1820 se anota en el libro de enterramientos como el sacerdote Don Pedro de las Haras, natural de Navarra que había muerto tras una larga enfermedad en el Hospital de Santiago, donde era capellán y en consecuencia tendría derecho a recibir sepultura. Sin embargo, siendo, tal y como aclara la anotación "singular bienhechor de esta iglesia", fue sepultado en su cripta tras la celebración de solemnes exequias ${ }^{65}$. Ya en 1692, el canónigo zaragozano D. Antonio de la Rua ${ }^{66}$, que actuaba como agente del Rey en la Curia romana había sido enterrado en el convento trinitario ${ }^{67}$. Mucho después, en 1818, esta misma sepultura recibiría los restos mortales de otro sacerdote español, Alfonso Torre ${ }^{68}$. También recibieron sepultura en 1740 D. Francisco Ramírez, natural de Murcia ${ }^{69}$ y en 1743 D. Ambrosio Albizu, que se identifica como del obispado de Pamplona y al que ya hemos citado anteriormente por habérsele permitido ocupar una de las sepulturas reservadas para los frailes ${ }^{70}$. Don Onofrio de Dalfau, archidiacono de la catedral de Barcelona y del que se apunta que era nativo de Cataluña es enterrado en 1706 en la cripta trinitaria. No se añade una información

${ }^{62}$ ASC, Libro de enterramientos. S., fol. 18v. anotación 119. Entierro en 1812 de un hijo del pintor José de Madrazo y anotación 120. Entierro de una hija del mismo con solo tres años de edad en 1813 en la misma sepultura de su hermano.

${ }^{63}$ ASC, Libro de enterramientos. S., fol. 19v. anotación 126. En noviembre de 1821 se entierra a Carolina Álvarez hija de D. José Álvarez escultor pensionado español. Fol. 23. Anotación 129. Con fecha de 6 de noviembre de 1823 se enterró a Carlos Álvarez Giovinetto de trece años hijo del mismo escultor.

${ }^{64}$ Pérez Estévez, R. Ma y González Martínez, R. Ma., Pretendientes y picaros españoles en Roma. Siglo XVIII. Valladolid, Secretariado de Publicaciones de la Universidad de Valladolid, 1992. El clima que describen estas investigadoras de la gran comunidad española residente en Roma en el siglo XVIII lleva a pensar que fueran muchos los que acabaran teniendo que recurrir a las iglesias de las distintas órdenes españolas en la ciudad para reposar en sus iglesias y cementerios.

${ }^{65}$ ASC, Libro de enterramientos. S., fol. 19v. anotación 124. También le celebraron exequias con la asistencia de la comunidad del hospital nacional donde era capellán.

${ }^{66}$ Este Antonio de la Rua debe ser Antonio Pérez de la Rua canónigo de Zaragoza, vicario general de Jaca y agente del rey Católico en la Curia romana.

${ }^{67}$ ASC, Libro de enterramientos. S., fol. 4v. anotación 32. Enterrado el 8 de febrero de 1696.

${ }^{68}$ ASC, Libro de enterramientos. S., fol. 19r. anotación 122. El 30 de abril de 1818 se enterró en la sepultura numero 28.

${ }^{69}$ ASC, Libro de enterramientos. S., fol. 12r. anotación 78. El siete de octubre de 1740 fue enterrado en la sepultura numero 7.

${ }^{70}$ ASC, Libro de enterramientos. S., fols. 12r-12v. anotación 81. 
adicional a este dato para saber los motivos que le llevaron a ser sepultado en esta iglesia y no en la de Monserrat con la que tendría una mayor afinidad ${ }^{71}$.

Aún así, la solidaridad en la muerte entendida en términos nacionales donde se podría expresar con mayor representación pública era en la celebración de las honras fúnebres en las que se daba un acompañamiento de parte de la comunidad española residente en Roma. Y eso quedó reflejado en los registros de los enterramientos de los hijos del escultor José Álvarez. En noviembre de 1821 se registra la anotación del sepelio de su joven hija Carolina y se hace mención expresa de que sus padres quisieron que se enterrara en "esta iglesia de españoles” y de que a sus exequias acudieron diplomáticos y artistas españoles ${ }^{72}$. De un modo muy parecido se toma nota del entierro de otro hijo del artista en 1823 e igualmente se dice que en sus oficios estuvieron los señores pensionados, en alusión a la condición socioeconómica de muchos de los artistas que vivían allí y de “otros de la nación española”73.

Entre la mucha y variada información que se puede ir extrayendo del estudio de este libro de enterramientos del convento de San Carlino es posible comprobar el modo en que estos religiosos manifiestan esa especial simbiosis cultural de un comunidad española fuertemente enraizada en Roma. Así es como la lengua utilizada en todo este documento es el italiano ${ }^{74}$. Aunque en alguna ocasión la lengua materna acaba apareciendo en algunas palabras que se enmiendan con una tachadura sobre el termino en español y su restitución por el mismo en italiano. También es habitual encontrar algunas anotaciones de enterramientos en que se recoge el dato de la hora de la muerte o el sepelio y se añade si se mide con el reloj italiano o español ${ }^{75}$.

${ }^{71}$ ASC, Libro de enterramientos. S., Fol. 6v. anotación 44. Entierro de Don Onofrio de Dalfau el 28 de marzo de 1706 en la sepultura número 30.

${ }^{72}$ ASC, Libro de enterramientos. S., fol. 19v. anotación 126. En noviembre de 1821 se entierra a Carolina Álvarez de catorce años de edad hija de D. José Álvarez escultor pensionado español y se añade que tanto él como su esposa, que era Flamenca, quisieron que se enterrara en esta iglesia de españoles.

${ }^{73}$ ASC, Libro de enterramientos. S., Fol. 23. Anotación 129. Con fecha de 6 de noviembre de 1823 se enterró a Carlos Álvarez Giovinetto de trece años hijo del mismo escultor con la asistencia de los señores pensionados y de otros de la nación española.

${ }^{74}$ Hay una curiosa excepción hecha en el encabezamiento del índice de los frailes enterrados que se escribe en español, aunque el resto del mismo está en italiano.

75 ASC, Libro de enterramientos. S., Fols. 5v-6r. anotación 42. Registro del entierro de D. Antonio Pacheco en que se informa que murió el domingo dos de diciembre de 1703 a las nueve de la mañana según el reloj español. ASC, Libro de enterramientos. S., Fol.7r. anotación 48. Registro del entierro de Orazzio Jaliani muerto el 26 de noviembre de 1708 después de las dos o tres de la mañana “del orologgio espagnuolo”. ASC, Libro de enterramientos. S., Fol. 10r. anotación 64. La marquesa Constanza Toruci de Ormani muere el uno de octubre de 1726 a las ocho hora 
La forma en que estos registros se van sucediendo deja ver claramente como va produciéndose el relevo en la labor de su registro en el libro de enterramientos. Obviamente producto del amplio arco cronológico que abarca es normal que fueran distintas personas las encargadas de llevar a cabo esta tarea, cuya identidad es difícilmente identificable. Hay alguna excepción como la del registro del entierro de Giovanna Salseti Giuliana, hermana de la orden que se entierra en 1756 y de cuya ejemplar vida y muerte da testimonio Fray Martino del Santísimo Sacramento $^{76}$. Ahora bien, hay algunas de estas anotaciones en que se dan unos datos mínimos sobre el difunto y el lugar en que es sepultado mientras que en otras se ofrece una información más variada sobre la persona su particular inclinación por elegir esta iglesia y no otra, si hicieron algunos legados especiales a la misma o incluso sobre el modo en que se llevó a cabo su entierro y celebración de exequias.

Obviamente se recogieron muchos detalles sobre el enterramiento del hijo del Duque de Uceda que por esos años tenía el cargo de embajador en Roma. Antonio de Pacheco de veinte años de edad muere el dos de diciembre de 1703 a las nueve de la mañana según el reloj español y sus restos mortales se colocaron en la sepultura número uno, donde ya estaban los del Cardenal Denoff. Se añade que el cadáver fue embalsamado y metido en tres cajas distintas, una de ciprés que se introdujo en una de plomo y esta a su vez en una de castaño decorada con gallones y tela en la que estaba bordada una cruz. Se cerraba esta última con dos llaves, una de las cuales la custodiaba el convento. En la caja de plomo se habían grabado una cruz y el epitafio en español ${ }^{77}$.

El citado Cardenal según consta en la anotación número treinta y cuatro del registro de difuntos seculares fue enterrado el veintidós de junio de 1697 en la sepultura número seis, es decir, una de las reservadas a los frailes trinitarios. Sin embargo sus restos debieron trasladarse a la número uno, donde después se colocarían los del hijo del embajador anteriormente referido ${ }^{78}$. El legado de este cardenal para con el convento debió ser generoso lo que justificaría que su lápida junto con un gran escudo de armas estén decorando el centro de lo que en su momento fue refectorio del convento y que ahora es sacristía. Justo a su lado se ha

italiana. ASC, Libro de enterramientos. S., Fol. 14r-14v. anotación 93. Registro del entierro de Da. María Vittoria Campanni que muere el 8 de febrero de 1763.

${ }^{76}$ ASC, Libro de enterramientos. S., Fol. 13r. anotación 88. Entierro de Giovanna Salseti Giuliana el 4 de octubre de 1756 en la sepultura número 38.

${ }^{77}$ ASC, Libro de enterramientos. S., Fols. 5v-6r. anotación 42. Se transcribe integro el epitafio en español.

${ }^{78}$ ASC, Libro de enterramientos. S., Fol. 
conservado una lápida de mármol blanco en que aún está legible parte del epitafio del arzobispo armenio Alejandro Aslam, que tras una larga estancia en Roma pidió ser enterrado en esta iglesia trinitaria en cuya comunidad había residido sus últimos quince meses de vida ${ }^{79}$.

También el de la Duquesa de Módena, Doña Laura Martinozzi Mazarini en julio de 1687 es un largo y detallado registro en que se explica que su cuerpo fue introducido en una caja de plomo en la que se grabó un epitafio y esta a su vez en otra caja de madera. La voluntad de esta señora con respecto al convento de San Carlino había sido plasmada en el testamento que otorgó en junio de 1681 y refrendada en un codicilo posterior. En ambos documentos dispuso una serie de legados que tendrían como beneficiaria a la comunidad trinitaria para de esta forma continuar tras su muerte el apoyo que esta había prestado en vida. Ya que tal y como consta en el largo registro del libro de enterramientos, siempre había estado pendiente de las necesidades del convento.

Sin embargo desde un principio se estableció que su cuerpo quedaría en depósito en su iglesia para que sus descendientes pudieran trasladarlo como de hecho se hizo el seis de septiembre de 1695 actuando el Abad Fossi como agente de su hijo, el Duque de Módena. Por esto el convento recibió treinta escudos además de una serie de legados piadosos que se han conservado hasta la actualidad en su archivo y que se tradujeron en sufragios por el alma de la difunta al menos hasta finales del siglo XVIII.

Es muy particular la atención que se da a los detalles de los enterramientos de alguna de las difuntas ligadas a la orden trinitaria. No en todas ellas se hace una extensa relación del modo en que se procedió a celebrar sus honras funerales y su sepelio, pero en el caso de la hermana Giovanna Salseti se enumera el modo en que fue amortajado su cadáver (con el habito de la orden y velo blanco largo) y se enumeran sus muchas cualidades así como los signos físicos que tras su muerte se suelen tener por prueba de su excelencia y virtud religiosa (no presentar rigor mortis, el color y la sonrisa en su cara que la asemejan con una persona plácidamente dormida) ${ }^{80}$. También se registra con pormenor el enterramiento de la hermana María Vittoria Campanni Santoro en una de las sepulturas reservadas a los frailes. Además del hábito y el velo blanco, se le cubrió la cara con un sutil velo, se le colocó un rosario en las manos y se le puso una corona de flores frescas a los

\footnotetext{
${ }^{79}$ ASC, Libro de enterramientos. S., Fol. 17r. anotación 110. Entierro del Sr. Alejandro Aslam el 20 de mayo de 1792 en la sepultura número 29.

80 ASC, Libro de enterramientos. S., Fol. 13r. anotación 88. Entierro de Giovanna Salseti Giuliana el 4 de octubre de 1756 en la sepultura número 38.
} 
pies, como símbolo de su virginidad. Al parecer había destacado esta dama en el campo de la óptica y de las matemáticas y en la práctica devocional y la teología. Fue una gran benefactora de la orden trinitaria y doto una fiesta con música en honor de Jesús Nazareno ${ }^{81}$.

Destaca entre todos los registros de los difuntos seglares la extensión y detalle con que se expone la virtuosa vida de Elisabetta Canori Mora y de igual modo se trata todo lo que se relaciona con su sepultura. Actualmente la antigua señalización de su enterramiento, una placa cerámica con su epitafio se conserva en una zona de exposición que el convento tiene dedicada a la beata. En 1825 se le reservó un lugar muy especial, bajo el altar del Beato Michele y de Santa Úrsula, en un sepulcro elevado sobre la solería de la cripta ${ }^{82}$.

La parte dedicada en este libro a los sepelios de seculares en San Carlino no es muy extensa, lo que se debe sin duda a que no son muchos los que recibieron sepultura en el mismo: 139 desde 1638 hasta 1863, a lo que se une la escasa superficie útil que se puede utilizar en la planta libre que tiene esta pequeña iglesia. Aun contando con el uso intensivo de las sepulturas, ya que hemos visto que son pocas las que se concedieron en propiedad, por lo que la mayoría se reutilizaban pasado un periodo de tiempo prudente. E incluso aportando las reservadas para los frailes por parte de personas ajenas a la orden.

Ahora bien para ayudar a clarificar toda esta información el religioso trinitario que llevara a cabo la labor de recopilación y registro de los enterramientos incluyó en el libro un dibujo de un sencillo plano de la iglesia subterránea con las distintas sepulturas numeradas. Simplificada la planta a su geometría esencial, se incluyen como referencias la ubicación de unas escaleras, una pequeña caseta que pudiera ser un panteón-osario y el altar principal de este espacio funerario. Se pueden apreciar una serie de rectángulos que representarían las sepulturas ordenados por filas paralelas al testero del altar. La primera y por tanto más cercana al mismo sólo tendría dos lugares de enterramiento, sin embargo en la segunda fila se amplían a seis, y en la tercera, cuarta y quinta a ocho cada una, reduciéndose otra vez a seis en la sexta fila, a cuatro en la séptima y a dos en la octava y última.

Si se remiten a los datos que se obtienen a la vista de este esquema de planta de la cripta trinitaria se puede observar una división en ocho trances de sepulturas que intentan adaptarse a la singular forma de la iglesia de Borromini. Pero para poder extraer alguna conclusión de su estudio debe compararse con la informa-

${ }^{81}$ ASC, Libro de enterramientos. S., Fol. 14v. anotación 93. Entierro de Da. María Vittoria Campanni Santoro el 9 de febrero de 1763.

${ }^{82}$ ASC, Libro de enterramientos. S., Fols. 20r-23r. anotación 128. 
ción que aportan los registros de enterramientos. Así parece que la separación que se ha reflejado entre las sepulturas del mismo trance debía corresponderse con la realidad, ya que en alguna ocasión se menciona que se enterró a alguien cerca de una sepultura ya ocupada sin especificar su número o que se enterró entre dos numeradas correlativamente. El margen que había entre ellas es lo que da crédito a anotaciones como la del sacerdote D. Pedro de las Haras "en el numero 32 y parte del 38 por ser de estatura muy alta" ${ }^{\text {}}$. Ya que ambas no aparecen perfectamente alineadas en este dibujo. Seguramente porque las cualidades gráficas del fraile que lo hizo no serían muchas, aunque si su voluntad de reflejar la realidad de su cripta.

Analizando los enterramientos que se practicaron en los distintos trances se observa que en el primero, inmediato al altar sólo recibieron sepultura cuatro personas, ya que era el espacio privilegiado por excelencia. En la segunda fila hay unas sepulturas reservadas para los frailes lo que no fue obstáculo para que se enterraran unos cuantos difuntos, que obligaba a colocar algunos en disposición vertical, en una estructura que debía ser parecida a una serie de nichos ubicados en una especie de bóveda funeraria subterránea.

En el tercer trance solo las sepulturas trece y dieciséis reciben más de tres cadáveres, aunque se respeta un periodo de tiempo prudente que distancia en el tiempo los sepelios como mínimo veinte años. Hay dos sepulturas, las número catorce y quince que se usan una única vez, aunque en ninguna de ellas se explique que sobre ellas había algún derecho de propiedad o de utilización exclusiva. En el cuarto trance la dinámica es muy similar, aunque sólo hay una sepultura, la número veintitrés que se abra en una ocasión. El quinto trance o fila tiene una utilización muy homogénea y cada una se usa mínimo en tres ocasiones. El sexto trance parece utilizarse con menos frecuencia, todas las sepulturas se abren para un único difunto excepto la treinta y tres y la treinta y cinco. El séptimo trance se utiliza regularmente, exceptuando la sepultura treinta y nueve en la que no consta se realizara ningún sepelio. Aunque esto pudiera ser un error en la numeración, ya que el treinta y nueve se usa dos veces y una de ellas es sobre una sencilla representación de algo que debía ser un panteón o un osario. El último trance que queda a los pies de la iglesia subterránea se usa con mucha frecuencia. Ahora bien no hay constancia documental en este libro de que este se utilizará como un espacio

${ }^{83}$ ASC, Libro de enterramientos. S., Fol. 19v. anotación 124. Entierro de D. Pedro de las Haras el 26 de julio de 1820 . 
reservado para los más pobres en los que se hicieran sepelios sin que la comunidad recibiera algún tipo de dinero en concepto de limosna por el mismo.

Este es un dato que no se aporta en ninguna de las anotaciones que se hicieron en este registro. No se menciona una cantidad en concepto de pago por una sepultura en propiedad o por los derechos de enterramiento en la misma. Solamente cuando se explica cómo se realizó el sepelio de Sor Giulia de la Santisima Trinidad en 1771 se añade que fue enterrada en el número cuarenta "por caridad". Y esta si se observa su ubicación en el dibujo de la planta de la iglesia está en un trance alejado del altar, pero no es el último, en el que por otro lado se enterraron miembros de la Familia Anivitti que debían tener una posición económica acomodada puesto que costearon sendas lápidas de mármol blanco.

En el libro se ha conservado pegado a la contraportada un documento del tamaño aproximado de una octavilla en que se enumeran una serie de servicios que ofrecía la comunidad trinitaria y un número que posiblemente sea la limosna establecida por el mismo. Sin embargo en el concepto sepultura hay una única cantidad lo que lleva a pensar que hubiera una cantidad fija por el mismo independientemente de cual fuera el trance en que se situara.

Aun así, o precisamente por esto. El estudio del libro de enterramientos de San Carlos alle Quattro Fontane es todavía una fuente esencial para acercarse a la interesante vida que desarrolló esta comunidad de religiosos españoles en el intenso periodo que suponen los siglos que transcurren desde aproximadamente la mitad del XVII hasta la mitad del XIX. 